fuentes documentales existentes sobre el siglo XVIII gaditano, tanto en los archivos nacionales, como, sobre todo, en los locales (Archivo Municipal, Catedralicio, Diocesano, Histórico Provincial y parroquiales), indicando cómo, en buena medida, mucha de la documentación conservada en los mismos se encuentra aún por explotar, por lo que su consulta puede deparar en el futuro más de una sorpresa al historiador.

Julio Pérez Serrano, profesor titular de Historia Contemporánea de la Universidad de Cádiz, disertaría sobre los frágiles fundamentos demográficos de la ciudad, a la que podemos definir sin duda alguna como un gigante con los pies de barro. El Cádiz dieciochesco era una ciudad sumamente insalubre, con unas tasas de mortalidad muy elevadas, y una natalidad ilegítima que llegó a alcanzar niveles sobrecogedores, por lo que solamente una continua inmigración de componentes foráneos podía garantizar el crecimiento demográfico de la ciudad.

Manuel Bustos Rodríguez, profesor titular de Historia Moderna de la Universidad de Cádiz, se centraría en dos aspectos claves para entender la vida del Cádiz dieciochesco, su actividad comercial, y su burguesía. El Cádiz del siglo XVIII era una ciudad con unas conexiones mercantiles extendidas no sólo al continente americano, sino a buena parte de los puertos europeos y mediterráneos, desarrollándose en su seno una importante colonia mercantil muchos de cuyos componentes eran de origen foráneo, lo que daría a la ciudad un ambiente abierto y cosmopolita.

Sin embargo, este Cádiz aparentemente próspero y rico, conocerá una cara oculta de pobreza y marginación puesta de relieve por María José de la Pascua Sánchez, profesora titular de Historia Moderna de la Universidad de Cádiz. En Cádiz existieron importantes bolsas de pobreza que las instituciones asistenciales eran incapaces de atender debidamente, a la vez que una (aunque cada vez menos numerosa) colonia de esclavos musulmanes y africanos, en tanto la delincuencia y la inseguridad constituían fenómenos cotidianos. Sin olvidar tampoco la situación de marginación en la que se encontraban las mujeres, muchas de las cuales tuvieron que afrontar una existencia sumamente precaria ante el abandono sufrido por sus cónyuges, muchos de los cuales marcharon hacia América en busca de una prosperidad y un enriquecimiento que casi nunca llegarían.
Arturo Morgado García se aproximó a la vida religiosa de la ciudad en el siglo XVIII. Una ciudad oficialmente ( $y$, en buena medida, también en la práctica) católica, pero en cuyo seno encontramos comportamientos y actitudes que no siempre se encuentran en sintonía con la ideología oficial: así, la presencia de una colonia protestante, o las desviaciones religiosas cometidas por la población católica de la ciudad y cuya existencia podemos detectar a través de las fuentes inquisitoriales.

Para complementar estas exposiciones teóricas se desarrollaron dos visitas, una al Archivo Histórico Provincial, dirigida por la profesora Guadalupe Carrasco González, y en la que contamos con la inestimable colaboración del personal del mismo, representado en la persona de su director, D. Manuel Ravina Martín; y una segunda al Museo Municipal dirigida por Juan Ramón Cirici Narváez, profesor de Historia del Arte de la Universidad de Cádiz, cuyo núcleo fundamental sería la maqueta de la ciudad construida en el último cuarto del siglo XVIII, que nos brinda una visión incomparable de lo que era urbanísticamente la ciudad durante dicho período.

Arturo Morgado García Director del Curso

\title{
SIMPOSIO INTERNACIONAL
}

\section{"Visigodos y Omeyas: un Debate entre la Tardoantigüedad y la Alta Edad Media"}

Durante los pasados días 21, 22 y 23 de Abril de 1999 se celebraron en Mérida, organizado por el Consorcio de la Ciudad Monumental, Histórico-Artística y Arqueológica de Mérida con la colaboración del Departamento de Arqueología del Centro de Estudios Históricos del Consejo Superior de Investigaciones Científicas, coordinados por los Dres. Caballero Zoreda y Mateos Cruz, el Simposio Internacional Visigodos y Omeyas: Un debate entre la Tardoantigüedad y la Alta Edad Media. Bajo este título subyace una de las polémicas más interesantes que actualmente se genera sobre la cultura de los siglos VI al X en toda la Península Ibérica, acentuada por la nueva corriente de investigación, frente a la tradicional visión "visigotista", que vincula la cultura de estas centurias con influencias de carácter islámico.

El Simposio, en mi opinión, podría dividirse en cuatro bloques, todos ellos interrelacionados. El primero, como punto de partida, a cargo de J. Arce, que habla sobre los antecedentes romanos de la cultura visigoda, el segundo donde se exponen casos concretos: Mérida, Córdoba, Cartagena, Santa María de Mijangos o Recopolis, el tercero en el que polemizan las dos posturas existentes, la "visigotista" defendida por Arbeiter y Morín de Pablos y la "innovadora" representada por Luís Real y Caballero Zoreda, apoyada entre otros, por Cruz Villalón y F. Arce. Por último, una visión histórica de este momento de transición a cargo de Acién Almansa, Manzano y Peña.

El Dr. J. Arce con su ponencia "Gothorum Laus Civilitas Custodia". Los visigodos conservadores de la cultura clásica: el caso de Hispania, expone el estado de la cultura, con sus pervivencias romanas, durante época visigoda en Hispania tomando como referencia la frase de Casiodoro "la gloria de los godos es el haber conservado la civilitas, la cultura, la civilización romana". Dentro de este balance 
Noticias y

cultural destaca la presencia de pizarras, usadas como ejercicios escolares, archivos, contratos, religiosos o copias de documentos oficiales. Según él, son el "mantenimiento de la civilización de lo escrito o del escrito".

El "segundo bloque" lo inicia el Dr. Marfil. Bajo el título "Córdoba de Teodosio a Abd al-Rahmán III" ofrece un panorama de la Corduba entre los siglos IV-VI, bastante novedoso, con los últimos hallazgos de "Cercadillas" así como las intervenciones realizadas en el recinto de la mezquita. Reseña la existencia de una importante oligarquía cristianizada interpretando el supuesto Palacio Imperial de Cercadillas, como posible sede del Palacio Episcopal Paleocristiano que estaría en uso hasta la segunda mitad del s. VI cuando se traslada a la iglesia de San Vicente cambiando ostensiblemente el urbanismo de esta zona.

La visión general de Mérida es ofrecida por el Dr. Mateos y M. Alba bajo el título de "De Augusta Emerita a Marida (s. VIIIX)". Describen los procesos de cambio que sufre la antigua capital de la Lusitania desde el siglo IV hasta el 868, la continuidad ocupacional con la presencia de nuevos elementos diferenciadores: cristianismo, islamización, etc.. El inicio de esta panorámica general comienza en el s. IV, época de grandes procesos constructivos, de como a partir del s. $\vee$ se va introduciendo paulatinamente el urbanismo cristiano. Durante el siglo VI nos hablan de la presencia de varios edificios religiosos en torno a la basílica de Santa Eulalia, del s. VII apenas existen datos. Siguiendo como referente la intervención arqueológica realizada en Morería, se documenta durante el s. VIII un corredor defensivo adaptándose, en parte, al entramado reticular romano que aún parece pervivir. Por último del s. IX ofrecen una somera visión con la destrucción de la muralla romana, la presencia de mezquitas, maqbaras y de una serie de complejos edificios de posible carácter civil.

Siguiendo esta línea expositiva el Dr. Lecanda con "Mijangos: la aportación de la epigrafia y el análisis arqueológico al conocimiento del altomedievo", expone un conjunto de yacimientos, cuyo conocimiento, a la luz de los resultados obtenidos en las últimas intervenciones arqueológicas, ha cambiado profundamente. Se centra, sobre todo, en Santa María de Mijangos, yacimiento visigodo que, según él, no tiene paralelos. Describe sus fases, evolución, etc. destacando la presencia de una basílica con enterramientos infantiles en el contraabside, así como un área cementerial con tres fases superpuestas que van desde el s. VII al X.
Sobre "Cartagena entre el mundo tardorromano y el mundo islámico", el Dr. Ramallo describe el barrio comercial de época bizantina asentado sobre el teatro romano, donde se individualizan hasta cuatro casas con calles aterrazadas preludio del posterior urbanismo de época islámica, barrio que será destruido en el año 625 por los godos.

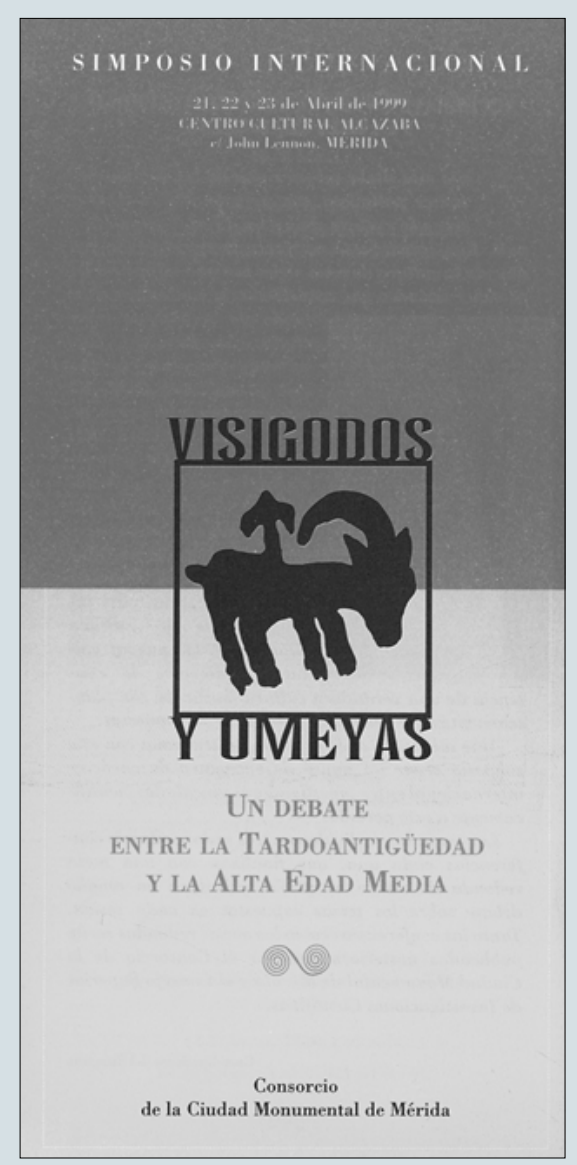

Por último, dentro de este apartado, el Dr. Olmo muestra en "De Recopolis a Racupel: Territorio y procesos de transformación social entre los siglos VI al IX", un ejemplo concreto donde se sintetiza la problemática de este momento. Para él, Recopolis supone un proceso de reflexión del poblamiento en época visigoda, la ciudad como un ente dinámico. Describe el yacimiento donde se constatan dos fases de época visigoda. La primera (s. VI) con el recinto amurallado, la iglesia y el conjunto palatino. La crisis del Estado visigodo queda reflejada en Recopolis con un cambio de funcionalidad en el conjunto palatino, además de un cambio en la trama urbana y una ruralización de la clase dirigente que nos indica una desestructuración, ya presente cuando los árabes llegan en el s. VIII.
En el "tercer bloque", entran en discusión las dos posturas existentes. Partiendo como modelo teórico que Santa María de Melque es obra del s. VIII, donde se pueden reconocer algunos elementos de influencia omeya. Esto ha consolidado un modelo que explica la materialidad de Melque y buena parte de la arquitectura considerada visigoda como consecuencia de la puesta en marcha de unos recursos creativos surgidos en el mundo musulmán a partir de la segunda mitad del s. VIII y cuyos referentes principales se encuentran en el arte sirio-omeya. Dentro de la nueva postura renovadora se enmarcan las intervenciones de Luís Real y Caballero Zoreda. El primero, en "Portugal: cultura visigoda e cultura moçárabe" repasando el estado de la cuestión en Portugal, pone en duda la metodología empleada debatiendo los procesos de creación de modelos. Por su parte, el Dr. Caballero en su ponencia "La arquitectura denominada de época visigoda ¿Es realmente tardorromana 0 prerrománica?, diserta sobre los condicionantes de la polémica, que los sintetiza en: dos modelos explicativos para una misma producción constructiva, el guión historiográfico con explicaciones mozarabistas contrapuestas a la anterior visigotista, proposiciones contradictorias y falta de un modelo consensuado con ciertas contradicciones o incoherencias (éstas las resume en: ausencia y acriticismo de los datos cronológicos, de análisis previos de yacimientos, de edificios y Corpus de la restante cultura material y excesiva importancia de la tipología estilística), relaciones tipológicas de igualdad estricta, tendencia a paralelizar con elementos pertenecientes al mismo grupo cronológico-cultural, evitando comparar con grupos distintos, propuestas forzadas, tipologías datadas o asimiladas al modelo propuesto $y$ mantenimiento del modelo a pesar de las propuestas contradictorias tipológicas. Describiendo los conceptos de paleocristiano y prerrománico destaca la importancia de atribuir qué es continuidad y qué novedad. Para él, como estrategia de investigación hay que definir unos tipos: Paleocristiano: urbano o rural y Prerrománico: mozárabes o cristianos. Dentro del grupo paleocristiano habla de basílicas urbanas, iglesias rurales, de Sta. Maria de Mijangos y, por último de las iglesias compartidas o convertidas en mozárabes así como de la restauración de iglesias en época prerrománica. Sobre la aportación islámica habla de varios condicionantes: economía dinamizadora, componente cultural, transmisión y existencia de unos medios técnicos, ademas de ¿residencias emirales? como transmisores de formas y técnicas. Referente al grupo mozárabe habla de la construcción o restauración de iglesias, po- 
niendo como ejemplo las explotaciones agrícolas del Trampal y Melque. Por último, dentro de estos tipos, señala el grupo cristiano con un hito cronológico visigodo: San Juan de Baños, así como de la tipología estructural prerrománica caracterizada por el abovedamiento. Estos postulados son defendidos por F. Arce que en "Nuevas perspectivas en la cultura material mozárabe" repasa la Historiografía tradicional sobre los estudios mozárabes planteando una revisión de los mismos, basándose para ellos en datos documentales y arqueológicos, así como las diferentes valoraciones efectuadas sobre la cultura material mozárabe intentando conocer cuáles son los fundamentos teóricos y metodológicos que las sustentan y donde se encuentran los puntos de discusión. Igualmente la Dra. Cruz Villalón con su intervención "El taller de escultura de Mérida. Contradicciones de la escultura visigoda", sigue en parte esa línea señalando que existen afinidades en los elementos islámicos y "visigodos". Por tanto, nos encontramos para ella, en un estado de confusión, siendo necesario, para salir de él abrir márgenes temporales y culturales. Contextualiza las piezas emeritenses de este momento y pone como ejemplo de esta problemática tres piezas concretas: el "Unicornio Caprino", que la lleva más allá del 7। I, la "placa del elefante" y el "grifo de Liño" que, para ella, es obra asturiana no visigoda.

La postura tradicional, como el título de su ponencia evidencia, "Alegato por la riqueza del inventario monumental hispanovisigodo", es defendida por el Dr. Arbeiter que, en contra de las nuevas corrientes, confirma y refuerza, desde la flexibilidad, su postura "visigotista". Pone para ello, varios ejemplos significativos: Santa Comba de Bande, San Pedro de la Mata, Santa María de Melque donde señala que la vía de trasmisión es la arquitectura paleobizantina, no la paleoislámica ya que, según él, el arte paleoislámico de Oriente (S. VII-VIII) se basa a su vez en el amplio tesoro de manifestaciones del pujante arte paleobizantino. Realiza una propuesta del proceso artístico seguido durante el s. VI con la intensificación en la cultura hispana del elemento bizantino a través de una vía emeritense de irradiación. Concluye que la pujanza del arte bizantino alrededor del s. VI fue de primer orden, dentro y fuera del dominio bizantino, y que este arte dejó su impronta tanto en lo hispanovisigodo como después en lo paleoislámico. No excluye que en época paleoislámica existiera una segunda fase de irradiación hacia Hispania pero la irradiación primera y principal de las corrientes bizantinas tuvo lugar seguramente en época hispanovisigoda y por vía directa.
Esta postura "visigotista" es igualmente avalada por los Dres. Barroso y Morín de Pablos que en "Temas y formulas iconográficas en la cultura hispanovisigoda (siglos VI-VIII)" hablan del lenguaje artístico propio de la escultura hispanovisigoda, desde sus orígenes, en la plástica paleocristiana, hacia una creciente orientalización del gusto derivado de la influencia bizantina. Destacan los obstáculos principales con los que se encuentra el estudio de la escultura: la simplificación y degeneración formal de diseños y la desaparición de los referentes artísticos (bizantinos), de como en la arquitectura se produce una multiplicación de espacios dentro de los templos. De la temática en la escultura hispánica de esta época señalan la importancia del escenario concluyendo que la decoración escultórica viene a ser un reflejo de una liturgia donde primaba el sentido mistérico.

Dentro del último bloque, que podríamos denominar "visión histórica" de este periodo, enmarcamos las intervenciones de los Dres. Acién, Manzano y Peña. El primero de ellos en "La herencia del postfeudalismo visigodo frente a la imposición del estado islámico", diserta sobre la continuidad de elementos feudales que tienen su origen en el mundo visigodo, y que serán enfrentados al desarrollo del estado cordobés que acabará aniquilándoles. Ello no implicará la desaparición total de dichos elementos, aunque sí serán residuales. Analiza la clase dirigente con continuidad tanto en los elementos eclesiásticos (sedes episcopales) como en medios aristocráticos. En este sentido, destaca la aparición de grandes linajes muladíes. Todo ello implica el mantenimiento de una cultura material propia en la que se incluyen lógicamente edificios. Entra en la "polémica" basada en elementos arquitectónicos relacionados con lo omeya indicando las contradicciones existentes debido al antagonismo de estas sociedades que, para el se resuelven con las connivencias existentes con el poder o por el carácter "transicional" de la arquitectura y decoración arquitectónica omeya.

El Dr. Manzano en la "La conquista del 7 I I: transformaciones y pervivencias" donde expone las referencias de las fuentes árabes a la ocupación y el final del reino visigodo indicando las distintas tomas de posición frente a una conquista según la procedencia e intereses de los diferentes autores. Parece claro que hubo sectores de la aristocracia visigoda que pactaron desde el primer momento con los conquistadores estableciendo acuerdos que, en algunos casos, llegaron a alianzas ma- trimoniales. Esta práctica contó con el rechazo de ciertos círculos indígenas especialmente eclesiásticos. Señala, al igual que el Dr Acién, la existencia de linajes muladíes, de origen rural que aseguraron el control de estas zonas con la conquista mediante pactos, de cómo el control de las ciudades fue más fácil contando incluso con la colaboración de la Iglesia y por último, como los intentos de centralización omeya en el s. IX provocaron fuertes reacciones debido al aumento de la presión fiscal y la imposición de servidumbre.

Por último, la intervención de la Dra. Peña versaba sobre "La formación de los reinos hispánicos? una sociedad en proceso de ¿transformación, ruptura o cambio?" enmarcada en el incipiente reino astur cuyo marco cronológico va del 7/ I/7/8-722 al 1035-1037. Sintetiza las dudas historiográficas existentes, señalando que la Península Ibérica no era ajena al Feudalismo. Como ella señala, "los altomedievalistas nos encontramos en una situación que se debate entre "espejismos historiográficos" y "debates distorsionados".

Las conclusiones finales del Simposio realizadas por los Dres. G. Ripoll, A. Azcárate y J.M. Souto, reflejan la dicotomía existente entre las nuevas propuestas y las tradicionales, caracterizadas ambas a juicio de estos autores, por su inmovilismo. Plantean como necesario el debate, el uso de una terminología correcta, la diversidad del material hermenéutico sin olvidar otros factores, colaboraciones más estrechas, enfoques pluridisciplinares debido a los diversos canales de trasmisión e influencias de estos procesos complejos, analizar los vínculos entre la Península Ibérica y el mundo franco, prestando especial atención a los canales de trasmisión continentales, ampliar las vías de trasmisión, destacar la evolución del paisaje rural al urbano, conocer los diferenciadores geográficos, tener en cuenta la importancia de las perduraciones, considerar la cultura andalusí con una definición diacrónica, dar a la arquitectura cristiana andalusí unas señas de identidad, tener en cuenta la importancia del sustrato romano, la fragilidad de las cronologías, siendo necesaria la revisión de muchos aspectos con absoluta rigurosidad de las fuentes, y de las reconstrucciones históricas.

La principal lección que se puede extraer, en palabras de L. Caballero, es que el debate apenas está iniciado...

Félix Palma García Consorcio de la Ciudad Monumental de Mérida 